Provided for non-commercial research and education use. Not for reproduction, distribution or commercial use.

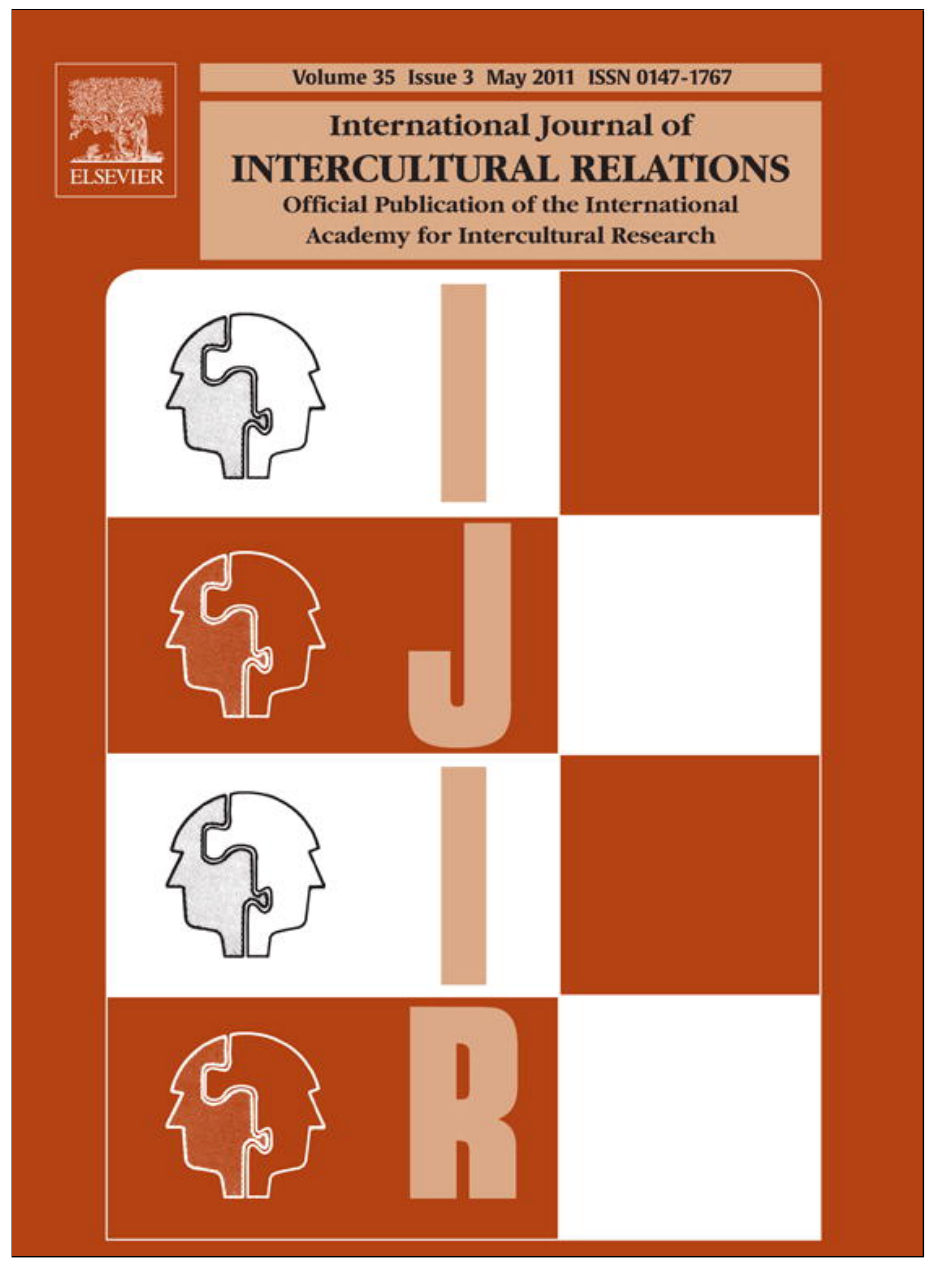

This article appeared in a journal published by Elsevier. The attached copy is furnished to the author for internal non-commercial research and education use, including for instruction at the authors institution and sharing with colleagues.

Other uses, including reproduction and distribution, or selling or licensing copies, or posting to personal, institutional or third party websites are prohibited.

In most cases authors are permitted to post their version of the article (e.g. in Word or Tex form) to their personal website or institutional repository. Authors requiring further information regarding Elsevier's archiving and manuscript policies are encouraged to visit:

http://www.elsevier.com/copyright 


\title{
Bringing together acculturation theory and intergroup contact theory: Predictors of Flemings' expectations of Turks' acculturation behavior
}

\author{
Kaat Van Acker*, Norbert Vanbeselaere \\ Center for Social and Cultural Psychology, Department of Psychology, Tiensestraat 102, Bus 3727, B-3000 K.U. Leuven, Belgium
}

\section{A R T I C L E I N F O}

\section{Article history:}

Accepted 8 June 2010

\section{Keywords:}

Intergroup contact

Acculturation expectations

Acculturation perceptions

Outgroup affect

\begin{abstract}
A B S T R A C T
The present paper explores Flemish majority members' expectations concerning the acculturation of Turkish minorities. We studied two kinds of antecedents: majority members' perceptions of Turkish minorities' acculturation behavior and their experiences of intergroup contact. The possible mediating role of outgroup affect was also investigated. 247 Flemish high school students completed a survey. Data were analyzed using path analyses. Results show that positive contact experiences and perceiving that Turkish immigrants make efforts to engage in contact with the host group and/or to adopt the host culture are associated with less negative affective reactions towards Turkish migrants. Perceiving that Turkish immigrants maintain their heritage culture is associated with more negative affective reactions. Our results further revealed that increased negative affective reactions are associated with less support for culture maintenance and for contact with the host group but with a higher demand for host culture adoption. The present results also show that expectations of contact engagement and expectations of host culture adoption cannot be considered as equivalent. This implies that results from studies using Berry's conceptualization of acculturation expectations (Berry, 2001) and results from studies using Bourhis' conceptualization of acculturation expectations (Bourhis, Moïse, Perreault, \& Senécal, 1997) are not directly comparable. Our data also clearly disconfirm the orthogonal structure of the fourfold acculturation model for majority members' acculturation expectations, suggesting that relying on the specific dimensions defining acculturation expectations may constitute a more valid approach to understand ongoing acculturation processes.
\end{abstract}

(c) 2010 Elsevier Ltd. All rights reserved.

\section{Introduction}

Western European societies have become increasingly diverse over the past 50 years, and Western societies and their inhabitants are struggling to cope with this evolution. Although the meaning and quality of intergroup relations between different ethnic groups within each country reflect distinct historical and political frameworks, host group orientations towards immigrants in Western European countries share some communalities (Phalet \& Kosic, 2006). For instance, a majority of the host group members in Belgium, France, Germany, the Netherlands and the United Kingdom believe that immigration should be limited (EVS, 2000) and that immigrants who want to settle in the host country should be committed to the way of life of the host culture (EVS, 2000; ESS, 2002).

The present paper explores Flemish majority members' expectations concerning the acculturation of Turkish minority group members. Large groups of Turkish immigrants came to Belgium in the late 1960s as foreign laborers. In the late 1970s

\footnotetext{
* Corresponding author.

E-mail addresses: Kaat.VanAcker@psy.kuleuven.be (K. Van Acker), Norbert.Vanbeselaere@psy.kuleuven.be (N. Vanbeselaere).
} 
and early 1980s, the international oil crisis caused economic inactivity among the first generation. Yet, immigration continued through family reunification and cross-border marriage. This change in the nature of immigration resulted in the permanent settlement of immigrant families and communities in Belgium. Since the 1990s, the second generation of immigrants is leaving school and entering the labour market in increasing numbers. At the same time, immigration from Turkey continues today, mainly through cross-border marriage (Phalet, Deboosere, \& Bastiaenssen, 2007). Currently, approximately $1.5 \%$ of the Flemish population is of Turkish origin (Belgian Census Data 1991-2001).

Despite their relative small numbers, Turkish minority group members constitute a salient and devalued immigrant group (Meeus, Duriez, Vanbeselaere, Phalet, \& Kuppens, 2009). Turkish minority group members are considered as Muslims, and attitudes towards Muslims tend to be projected on Turkish minorities. Recent findings show that $46 \%$ of the Flemish voters agree with the statement that Islamic culture does not contribute to European cultures, $37.2 \%$ disagree with the statement that most Muslims in Belgium respect European culture and lifestyle and $42 \%$ consider Islamic culture and history as more violent than other cultures (Billiet \& Swyngedouw, 2009). These feelings of threat and apparent lack of appreciation may fuel support for more restrictive immigration policies and resistance against minorities' culture maintenance. This rejection of cultural diversity is clearly manifested by the chairman of the "Vlaams Belang", a Flemish radical right-wing party, who stated that "In Flanders no immigrants, Francophones or others may be expelled, on the precondition that they adapt to our language and culture. If they do not wish to adapt, we will insist firmly on their return" ("Boxing gloves back," 2009). The statement of the Vlaams Belang chairman communicates that assimilation should be the final goal for acculturating minorities and according to a recent study (Vanbeselaere, Meeus, \& Boen, 2007) one-third of the Flemish majority group agrees with this position with respect to Turkish immigrants. These acculturation expectations of the majority group differ largely from what Turkish minority members themselves want (Snauwaert, Soenens, Vanbeselaere, \& Boen, 2003; Vanbeselaere et al., 2007), and this disagreement may result in intergroup tensions and conflict. It is important therefore to study where majority members' expectations concerning the acculturation of members of a particular minority group come from. Knowledge of these antecedents may offer possibilities to alter majority members' expectations and to bridge the gap between the positions of the host group and this minority group.

The present paper studies two kinds of antecedents: majority members' perceptions of Turkish minority members' acculturation behavior and episodes of intergroup contact. The possible mediating role of outgroup affect (e.g., threat, trust, sympathy) is also investigated.

\subsection{Acculturation theory: a categorical or a dimensional approach?}

Early studies of acculturation focused on the acculturation of immigrant groups, and on how immigrants orient themselves towards their heritage culture and the host culture. According to Berry $(1980,2001)$, immigrants are faced with two fundamental issues, which we will call acculturation dimensions. The first acculturation dimension refers to maintenance of the heritage culture ("Do I consider it important to maintain my heritage culture?"), and the second dimension refers to contact with the majority/host group ("Do I consider it important to engage in contact with the host group?"). On the basis of the answers to these two questions, four acculturation strategies are distinguished. Integration means that immigrants value maintenance of their heritage culture and that they also want to engage in regular contact with the host group. Assimilation occurs when immigrants do not insist on maintaining their cultural heritage, but they value relationships with the host group. Separation refers to a combination of preservation of one's heritage culture and avoidance of contact engagement with the host group. Marginalization is characterized by a loss of cultural and psychological connectedness with both the heritage culture and the host group.

Bourhis, Moïse, Perreault and Senécal (1997) argued however that the two acculturation dimensions introduced by Berry, one referring to cultural maintenance and the other to intergroup contact, touch upon different psychological phenomena which makes it questionable to combine them. Immigrants' position on the cultural maintenance dimension refers to an attitude towards culture whereas their position on the contact dimension refers to a behavioral intention. Bourhis et al. proposed then to replace contact with the host group by adoption of the host culture resulting in two acculturation dimensions defined as cultural attitudes.

Although the framework that defines the acculturation strategies is presumed to be universally applicable, this does not imply that different immigrant groups in different contexts are faced with the same acculturation tasks (Berry, Kim, Power, Young, \& Bujaki, 1989). The meanings of heritage culture maintenance, host culture adoption and contact engagement with the host group emerge within the relationship between the specific immigrant and host group and need not be the same for both groups.

Berry (Berry, 2001; Berry, Kalin, \& Taylor, 1977) and Bourhis (Bourhis et al., 1997) pointed out that not only the acculturation strategies of immigrants but also the acculturation expectations of members of the receiving society have to be studied. Host society members' acculturation expectations are defined by similar dimensions as the ones that determine minority members' acculturation strategies (Berry, 2001; Bourhis et al., 1997): approval of immigrants' culture maintenance and expectations of regular contact of minority members with the host group (the Berry model) or approval of immigrants' culture maintenance and expectations of host culture adoption (the Bourhis model). A combination of majority members' position on these two dimensions then again results in four different categories: integration, assimilation, separation, and marginalization. Several studies reported that majority members who expect minorities to integrate hold more favorable 
intergroup attitudes (e.g., less feelings of threat, racism and rejection; less social distance) than majority members who expect assimilation, separation or marginalization (e.g., Montreuil \& Bourhis, 2004; Snauwaert, 2002). In these studies the respondents were always classified into one of four acculturation categories by combining their position on the two underlying dimensions (e.g., Montreuil \& Bourhis, 2004; Piontkowski, Florack, Hoelker, \& Obdrzálek, 2000; Snauwaert et al., 2003; Zagefka \& Brown, 2002). Hence, for any relationship between acculturation strategies and affective intergroup attitudes it is unclear whether affective intergroup attitudes are related to only one or to both underlying acculturation dimensions (see Rudmin, 2003). Moreover, results obtained with Berry's acculturation model and results obtained with Bourhis' acculturation model cannot be compared in a meaningful way as long as it is not established how contact with the host group and adoption of the host culture relate to each other and how both relate to outcome variables. Finally, the combination of the two acculturation dimensions into discrete categories is based upon the assumption that these underlying acculturation dimensions are independent (Berry, 2001, but see Rudmin, 2003 for a critique). Many studies based on Berry's model or on Bourhis' model rely on midpoint or median split procedures to construct composite acculturation attitudes without reporting the correlation between the underlying dimensions (e.g., González, Sirlopú, \& Kessler, in press; Rohman, Florack, \& Piontkowski, 2006; Zagefka \& Brown, 2002). However, recent studies among majority members reveal that these underlying dimensions may be related rather than orthogonal dimensions (Meeus, Braeken, et al., 2009; Zagefka, Brown, \& González, 2009). Furthermore, the nature of the relationship between the acculturation dimensions underlying the majority expectations seems to depend upon which acculturation dimensions are used. One study revealed a positive correlation between expectations of contact engagement and approval of culture maintenance (Zagefka et al., 2009). However, another study revealed a negative relation between expectations of host culture adoption and approval of culture maintenance (Meeus, Duriez, et al., 2009).

In order to gain more insight into these issues, the present study explores the antecedents of Flemish majority members' position on three acculturation dimensions: approval of culture maintenance, expectations of contact with the host group and expectations of culture adoption.

\subsection{Acculturation perceptions as antecedents of majority acculturation expectations}

The position of members of a majority groups on the three acculturation dimensions may at least partly be determined by the position of members of the relevant minority group on these dimensions. However, it are not so much immigrants' actual acculturation preferences but rather what is perceived by the majority group that will inform majority members' own position (Van Oudenhoven, Prins, \& Buunk, 1998; Zagefka \& Brown, 2002). Thus, the positions of majority members on the three acculturation dimensions are at least partly a psychological response to the perceived positions of members of a particular minority group. For instance, when members of a particular minority group are perceived as having a strong inclination to maintain their own culture, majority members can respond to this perceived behavior either by tolerating culture maintenance or by disapproving it. Which response is likely to ensue is determined by majority members' affective reactions on the perceived position of this minority group on the acculturation dimensions (Zagefka, Brown, Broquard, \& Martin, 2007).

\subsubsection{Acculturation perceptions and outgroup affect}

With regard to culture maintenance, the more members of a specific immigrant group are perceived as maintaining their heritage culture, the more majority members see them as threatening and the less they like them (Stephan, Ybarra, Martinez, Schwarzwald, \& Tur-Kaspa, 1998; Van Oudenhoven \& Eisses, 1998; Van Oudenhoven et al., 1998; Verkuyten \& Thijs, 2002). On the contrary, the perception that members of an immigrant group actively search for contact with majority members or that they are willing to adopt (parts of) the host culture signifies positive approach tendencies that may well be reciprocated in terms of positive affect (Zagefka et al., 2007). Consistent with this prediction, one vignette study showed that Italian host members react more positively towards minorities who chose an assimilation strategy than towards minorities who chose separation or marginalization (Kosic, Mannetti, \& Sam, 2005).

\subsubsection{Outgroup affect and majority members' acculturation expectations}

Majority members' feelings towards a particular minority group are expected then to influence the position they take on the dimensions underlying their acculturation expectations. With regard to the culture maintenance dimension, rejection of culture maintenance constitutes a hostile reaction towards immigrants (Judd, Park, Ryan, Brauer, \& Kraus, 1995). Such hostile reactions occur more frequently when the outgroup is experienced as threatening the ingroup (Van Zomeren, Fischer, \& Spears, 2007). Thus, more negative affect is expected to be associated with more disapproval of culture maintenance (Zagefka et al., 2007).

With regard to expected contact with the host group, Mackie, Devos and Smith (2000) found that feelings of fear are associated with a tendency to move away from the outgroup. Additionally, although most contact researchers agree that there is a causal path from contact to prejudice, they also accept the existence of a significant path from negative attitudes towards avoidance of contact (Pettigrew, 1998; Pettigrew \& Tropp, 2006). Negative outgroup affect is thus expected to be associated with lower expectations concerning contact engagement (Zagefka et al., 2007).

The relationship between negative outgroup affect and expected culture adoption is more ambiguous. Majority members who feel threatened by an immigrant group will tend to react in a more hostile manner towards this immigrant group (Van 
Zomeren et al., 2007). With regard to host culture adoption this may either involve wanting no adoption at all, so that the threatening immigrant group is excluded from the host culture. Or this may involve requesting high levels of adoption of the host culture, so that cultural differences would become negligible, At the same time such a position provides a justification for further discrimination and exclusion of those members of the immigrant group who are perceived as refusing to adopt the majority culture. The latter option is clearly more prevalent in Flemish public discourse with respect to Turkish minorities, as illustrated in Section 1 of this paper, and only a very small percentage of the Flemish host group (4\%) does not expect from Turkish minorities that they adopt the host culture (Vanbeselaere et al., 2007). Therefore, we expect that majority members' negative affective reactions towards Turkish minorities will be associated with a stronger request for culture adoption.

\subsection{Intergroup contact as an antecedent of majority acculturation expectations}

Quantity and quality of intergroup contact constitute the second kind of antecedents that we will explore. The fact that intergroup contact is a successful means to ameliorate outgroup attitudes constitutes a first reason to include it as a predictor (Pettigrew \& Tropp, 2006). Moreover, intergroup contact theory suggests that affective processes play a very important role in explaining the effect of contact on outgroup attitudes (Miller, Smith, \& Mackie, 2004; Tropp \& Pettigrew, 2005). We will explore therefore how intergroup contact affects the positions of majority members on the three dimensions underlying acculturation expectations. Up to now, several acculturation researchers have already studied the relationship between intergroup contact and different acculturation expectations (González et al., in press; Montreuil \& Bourhis, 2004; Piontkowski et al., 2000), but no study has looked at the relationship between intergroup contact and the position on the different dimensions underlying acculturation these expectations.

An additional reason to include this potential antecedent of majority members' acculturation expectations is that there may be considerable conceptual overlap between the quantity and quality of intergroup contact as reported by host members and majority members' perception of minorities' contact engagement. The quantity and quality of intergroup contact concern majority members' individual experiences of intergroup contact while perceived contact engagement involves majority members' impression of immigrants' contact behavior as a group. We wonder to what extent perceived contact engagement and self-reported quantity and quality of intergroup contact constitute different constructs, to what extent they are correlated and to what extent they predict unique variance in outgroup affect.

\subsubsection{Intergroup contact and outgroup affect}

Positively experienced intergroup contact is expected to enhance positive feelings such as sympathy and trust (e.g., Aberson \& Haag, 2007; Batson et al., 1997) and to reduce negative feelings such as threat and insecurity (e.g., Aberson \& Haag, 2007; Stephan et al., 2002). But what is the effect of the mere quantity of contact: does more contact always result in more positive relations or does the contact effect depend upon the affective quality of the contact experience? Pettigrew and Tropp (2006) concluded from their meta-analysis that there exists a direct positive effect of contact quantity that is independent of contact quality. At the same time, several authors argue that the effect of contact depends on pre-existent attitudes (Amir, 1969), the broader context in which the contact takes place (Allport, 1954; Pettigrew, 1998) or group norms (Wright, Aron, McLaughlin-Volpe, \& Ropp, 1997). In order to formulate predictions, we take into account that the present study focuses on the Flemish acculturation situation and that Turks are the immigrant group that is concerned. Turks constitute one of the most devalued immigrant groups in Flanders and many Flemings associate them with lower socio-economic status, criminality and a disrespect for gender equality (Snauwaert, 2002). Hence, the social context within which intergroup contact takes place is quite negative. Within such a negative context the mere quantity of contact with Turks may even become associated with increased threat and anxiety, speaking against the established positive effect of contact quantity (Pettigrew \& Tropp, 2006). To allow for both competing hypotheses, no specific prediction is formulated with respect to the effect of quantity of intergroup contact.

\subsection{Proposed model}

The model proposed in Fig. 1 depicts our study hypotheses. The quality of intergroup contact (H1), perceived contact engagement (H2) and perceived culture adoption (H3) are expected to be associated with less negative outgroup affect. Perceived culture maintenance is hypothesized to be associated with more negative outgroup affect (H4). Negative outgroup affect is expected to be associated with less approval of culture maintenance (H5) and with lower expectations concerning contact engagement (H6) but with higher expectations concerning culture adoption (H7). To control for interrelations between the included variables, all initial variables were allowed to covary. All outcome variables were also allowed to covary. After testing the proposed model (see Fig. 1), several alternative models will be tested.

The contributions of the present study are threefold. First, by assessing the dimensions underlying the Berry model and the Bourhis model it can be established whether contact with the host group and host culture adoption are equivalent dimensions or not, and this for acculturation expectations as well as for acculturation perceptions. Second, in order to take the criticisms of Rudmin and Ahmadzadeh (2001) into account, we examine the relationship between each of the acculturation dimensions and affect towards the outgroup instead of examining the relationship between combinations of these dimensions and outgroup affect. Third, the present research explores whether quantity and quality of intergroup 


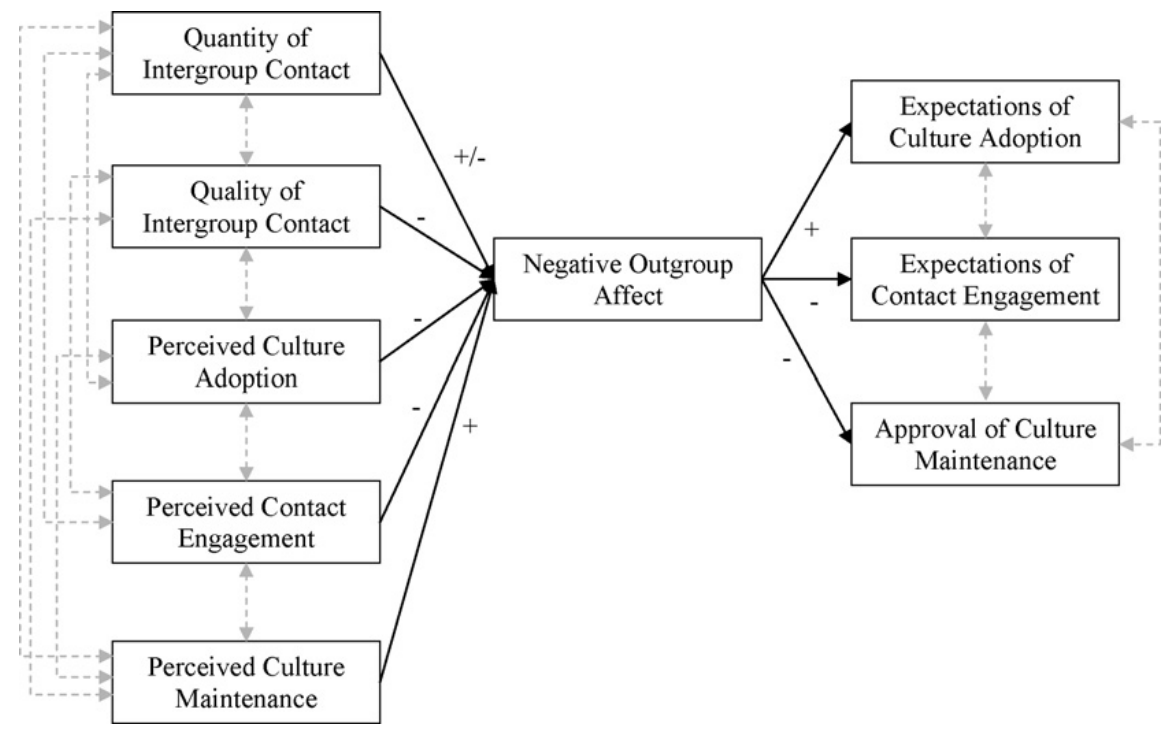

Fig. 1. Hypothesized model linking self-reported quantity and quality of contact, perceived culture adoption, perceived contact engagement and perceived culture maintenance to host members' expectations of culture adoption, expectations of contact engagement and approval of culture maintenance. Negative outgroup affect serves as mediator.

contact and perceived contact engagement do or do not constitute separate constructs. Therefore, we study to what extent each of these variables predicts unique variance in outgroup affect. Hence, we explore whether acculturation theory and the socio-psychological theory of intergroup contact complement each other in explaining majority members' acculturation expectations.

\section{Method}

\subsection{Participants and procedure}

247 Flemish high school students in the second or third grade of a general academic track (96 men, 151 women; $M_{\text {age }}=16.45, S D=1.26$ ) completed a survey during regular class time in the presence of a researcher and a class teacher. The survey took approximately $50 \mathrm{~min}$ (one class hour) to complete and contained a variety of measures related to acculturation and immigration processes. We present here only the items and variables that are relevant to our research questions. All items were answered on five point Likert-type scales ( 1 = strongly disagree, $5=$ strongly agree). At the beginning of the questionnaire the target group was defined as Turks who live and work in Belgium and who will continue to do so in the future. The participating classes contained also six students who identified as non-Belgian. Two of these identified themselves as Turks. In the Flemish city where the study was conducted approximately $4 \%$ of the citizenship is of Turkish origin.

\subsection{Measures}

\subsubsection{Acculturation expectations and perceptions}

Following the psychometric recommendations of Rudmin and Ahmadzadeh (2001) and in line with previous research (e.g., Phalet, Derycke, \& Swyngedouw, 1999; Piontkowski et al., 2000; van de Vijver, Helms-Lorenz, \& Feltzer, 1999) the dimensions underlying acculturation expectations and acculturation perceptions were assessed separately with simple straightforward single items. For the dimensions underlying acculturation expectations the items were: "I consider it important that they have positive and regular contact with Belgians" (expectations of contact engagement with the host group), "I consider it important that they adopt at least partially the Belgian culture" (expectations of host culture adoption), "I approve that they maintain their own culture" (approval of immigrants' culture maintenance). For the dimensions underlying acculturation perceptions, the items were: "I think that most of them maintain their own heritage culture" (perceived culture maintenance); "I think that most of them have good and regular contacts with Belgians" (perceived contact engagement); and "I think that most of them partially adopt the Belgian culture" (perceived culture adoption). These items refer to the acculturation dimensions as outlined by Berry (2001) and by Bourhis et al. (1997).

\subsubsection{Intergroup contact}

Quantity of contact was assessed with one item ("How often do you have direct contact with Turks?"). Three items measured contact quality $(\alpha=.82)$. One item questioned the number of outgroup friends (i.e. "How many Turkish friends do you have?"). The two other items questioned the positivity of experienced contacts (i.e. How positive were your contacts with Turks?") and the motivation to engage in contact (i.e. How strongly are you inclined to look for contact with Turks?"). 
Table 1

Correlations, means, and standard deviations for all study variables.

\begin{tabular}{|c|c|c|c|c|c|c|c|c|c|}
\hline & 1. & 2. & 3. & 4. & 5. & 6. & 7. & 8. & 9. \\
\hline 1. Approval of immigrants' culture maintenance & - & & & & & & & & \\
\hline 2. Expectations of contact engagement & $.264^{* * *}$ & - & & & & & & & \\
\hline 3. Expectations of culture adoption & $-.177^{* *}$ & $.175^{* *}$ & - & & & & & & \\
\hline 4. Perceived culture maintenance & -.119 & .005 & .012 & - & & & & & \\
\hline 5. Perceived contact engagement & $.340^{* * *}$ & $.287^{* * *}$ & -.044 & $-.203^{* *}$ & - & & & & \\
\hline 6. Perceived culture adoption & $.340^{* * *}$ & $.159^{*}$ & -.050 & $-.433^{* * *}$ & $.463^{* * *}$ & - & & & \\
\hline 7. Quantity of intergroup contact & $.214^{* *}$ & $.134^{*}$ & -.031 & -.095 & .114 & $.141^{*}$ & - & & \\
\hline 8. Quality of intergroup contact & $.401^{* * *}$ & $.369^{* * *}$ & -.072 & -.069 & $.436^{* * *}$ & $.310^{* * *}$ & $.380^{* * *}$ & - & \\
\hline 9. Negative outgroup affect & $-.599^{* * *}$ & $-.400^{* * *}$ & $.176^{* *}$ & $.222^{* * *}$ & $-.449^{* * *}$ & $-.455^{* * *}$ & $-.282^{* * *}$ & $-.643^{* * *}$ & - \\
\hline$M$ & 3.37 & 4.17 & 3.95 & 3.79 & 3.06 & 2.85 & 2.75 & 2.82 & 2.72 \\
\hline$S D$ & 1.058 & .85 & .90 & .89 & 1.060 & .10 & 1.01 & .89 & .83 \\
\hline
\end{tabular}

Note: $N=247$.

${ }^{*} p<.05$.

** $p<.01$.

${ }^{* * *} p<.001$.

\subsubsection{Outgroup affect}

We measured negative outgroup feelings as well as positive outgroup feelings. Six items assessed negative affect $(\alpha=.88)$. Three items concerned realistic and symbolic threat emanating from Turks (Stephan et al., 2002): 'Their presence forms a threat to our culture and traditions', 'They threaten the employment of Flemish people.', 'Most of them are here because they want to profit from our social security system'. One item addressed feelings of insecurity ('Because of their presence, I feel unsafe when walking on the streets'), one item questioned distrust ('In general, you can't trust these immigrants.') and one item addressed the wish to exclude immigrants from Belgian society ('Belgium should never have allowed these immigrants into the country.'). Positive affect was measured with four items tapping feelings of admiration, trust, empathy and one item expressing the overall positivity of respondents' feelings towards citizens of Turkish descent $(\alpha=.84)$.

Inspection of descriptive statistics revealed that the positive affect scale $(M=2.95, S D=.86)$ and the negative affect scale $(M=2.50, S D=.89)$ were strongly negatively correlated $(r=-.78, p<.001)$. Principal component analysis on all ten affect items revealed one component (eigenvalue 5.75) which explained $57.50 \%$ of the variance in the data. Therefore, we retained one combined measure of outgroup affect $(\alpha=.92)$ with higher values indicating more negative and less positive affect.

The means, standard deviations and intercorrelations of all variables are reported in Table 1 . The mean values on approval of cultural maintenance $(M=3.37, S E=1.058)$ and on expectations of culture adoption $(M=3.95, S E=.90)$ reveal that our participants have a stronger preference for culture adoption than for culture maintenance $(t(246)=6.083, p<.001)$. This pattern is in line with findings from the World Value Survey (2000) in which $75 \%$ of the participating Belgians believed it to better for their society that immigrants take over the customs of the host society than that they maintain distinct customs and traditions.

\section{Results}

\subsection{Equivalence of Berry's and Bourhis' acculturation models}

Berry's model defines majority members' acculturation expectations by combining their positions on two dimensions: whether or not members of the majority group approve culture maintenance by the minority group and whether or not they expect that minority members establish contact with the host group. Bourhis replaced expectations of contact engagement by expectations of culture adoption. This implies that results from studies using Berry's model and results from studies using Bourhis' model are only comparable if expectations of contact engagement and expectations of culture adoption are equivalent dimensions.

Our data (see Table 1) reveal that the correlation between expectations of contact engagement and expectations of culture adoption is indeed significantly positive $(r(247)=.18, p<.01)$. However, the size of the correlation is so small that the equivalence of these two acculturation dimensions cannot be accepted. This contention is certainly corroborated by the patterns of correlations between these two dimensions and other variables. Expectations of contact engagement are positively related to approval of culture maintenance $(r(247)=.26, p<.001)$ and negatively to negative outgroup affect $(r(247)=-.40$, $p<.001)$. Expectations of culture adoption are negatively related to approval of culture maintenance $(r(247)=-.18, p<.01)$ and positively to negative outgroup affect $(r(247)=.18, p<.01)$.

When we look at the patterns obtained for majority members' perceptions of Turkish immigrants' acculturation behavior, a clearly different pattern emerges. Perceived contact engagement and perceived culture adoption are positively and strongly correlated $(r(247)=.46, p<.001)$, suggesting that these dimensions may be used as equivalents. This contention is corroborated by the patterns of correlations between these two dimensions and other variables. Majority members' perceptions of Turkish minority members' contact engagement are negatively related to their perceptions of Turkish minority members' culture maintenance $(r(247)=-.20, p<.01)$ and to negative outgroup affect $(r(247)=-.44, p<.001)$. Majority 
members' perceptions of host culture adoption by the Turkish minority group are also negatively related to their perceptions of minority members' culture maintenance $(r(247)=-.43, p<.001)$ and to negative outgroup affect $(r(247)=-.45$, $p<.001)$.

In sum, the results of our Flemish sample, reveal that for acculturation expectations the dimensions underlying Berry's model and the dimensions underlying Bourhis' model are not equivalent. For acculturation perceptions, the dimensions underlying Berry's model and the dimensions underlying Bourhis' model may be seen as equivalent.

\subsection{The orthogonal structure of Berry's and Bourhis acculturation models}

Berry's and Bourhis' acculturation models draw on the assumption that the dimensions underlying acculturation expectations and perceptions are independent. Our data however disconfirm the orthogonal structure for both acculturation expectations and perceptions. For acculturation expectations, the two dimensions underlying Berry's model, approval of culture maintenance and expectations of contact engagement are not independent but significantly correlated $(r(247)=.26$, $p<.001)$. The two dimensions underlying Bourhis' model, approval of culture maintenance and expectations of host culture adoption are also significantly correlated $(r(247)=-.18, p<.01)$ but in the opposite direction.

For acculturation perceptions, the two dimensions underlying Berry's model, majority members' perceptions of immigrants' culture maintenance and majority members' perceptions of contact engagement, are significantly negatively correlated $(r(247)=-20, p<.01)$. The two dimensions underlying Bourhis' model, majority members' perceptions of immigrants' culture maintenance and majority members' perceptions of immigrants' host culture adoption are also significantly negatively correlated $(r(247)=-.43, p<.001)$.

Because our results reveal that for our sample the dimensions underlying acculturation expectations and perceptions are not orthogonal and Berry's and Bourhis' model are not equivalent we focus on the dimensions underlying the acculturation expectations and perceptions instead of on the composite categories to explore the antecedents of Flemish majority members' acculturation expectations.

\subsection{Testing the proposed model}

\subsubsection{Model testing}

To test the model proposed in Fig. 1, path analyses were conducted using AMOS software (Arbuckle \& Wothke, 1999) and maximum likelihood estimation. Model fit was assessed with a joint consideration of the chi-square statistic, the Comparative Fit Index (CFI), Goodness of Fit Index (GFI), the Root Mean Square Error of Approximation (RMSEA) and the Standardized Root Mean Square Residual (SRMR), which represents the average absolute correlation residual. Good model fit is evidenced by a non-significant chi-square, a CFI of at least .95, a GFI of at least .95, a RMSEA smaller than .05 and a SRMR of .05 or less (Kline, 1998).

The proposed model had a good model fit $\left[\chi^{2}(15, N=247)=17.36, p=.30 ; C F I=1.00, G F I=.99, R M S E A=.025, S R M R=.033\right]$. Looking at the regression coefficients, our hypotheses received strong support. Quality of intergroup contact $(\beta=-.51$, $p<.001)$ was associated with less negative outgroup affect $(\mathrm{H} 1)$. Perceived contact engagement $(\beta=-.12, p<.05)$ and perceived culture adoption $(\beta=-.19, p<.001)$ were also associated with less negative feelings (H2, H3). The mere quantity of intergroup contact $(\beta=.04, p=.44)$ appeared to be unrelated to negative feelings. Finally, perceived culture maintenance slightly increased Flemish majority members' negative feelings towards Turkish immigrants $(\beta=.09, p=.057)(\mathrm{H} 4)$. The four exogenous variables together explained $50 \%$ of the variance in outgroup affect. Next, negative outgroup affect - as predicted - was associated with lower expectations of contact engagement $(\beta=-.38, p<.001)(\mathrm{H} 6)$ and less approval of Turkish immigrants' culture maintenance $(\beta=-.60, p<.001)(\mathrm{H} 5)$. Negative outgroup affect was associated with stronger expectations of host culture adoption $(\beta=.18, p<.01)(\mathrm{H} 7)$. All six predictors together explained $15 \%$ of the variance in Flemish host members' expectations of contact engagement, $38 \%$ of the variance in approval of culture maintenance but only $3 \%$ of the variance in expectations of host culture adoption. Standardized estimates of the model are presented in Fig. 2 and unstandardized estimates are presented in Table 2.

\subsubsection{Mediation}

To further examine the mediating role of negative outgroup feelings, Sobel tests for indirect effects within the SEM model (MacKinnon, Lockwood, Hoffman, West, \& Sheets, 2002) were calculated. For Flemish host members' expectations of contact engagement the indirect effects of the quality of intergroup contact $(\beta=.20, z=5.36, p<.001)$, of perceived contact engagement $(\beta=.044, z=2.01, p<.05)$ and of perceived culture adoption $(\beta=.072, z=3.038, p<.01)$ were significant, indicating that these variables induce affective reactions towards Turks that influence Flemish majority members' expectations of contact engagement. The indirect effect of perceived culture maintenance was only marginally significant $(\beta=-.036, z=-1.84$, $p=.066)$.

For Flemish majority members' expectations of host culture adoption significant indirect effects were observed for the quality of intergroup contact $(\beta=-.091, z=-2.69, p<.01)$ and perceived culture adoption $(\beta=-.033, z=-2.17, p<.05)$. The indirect effects of perceived contact engagement $(\beta=-.020, z=-1.69, p=.090)$ and perceived culture maintenance on expectations of culture adoption failed to reach significance $(\beta=.017, z=1.58, p=.11)$. 


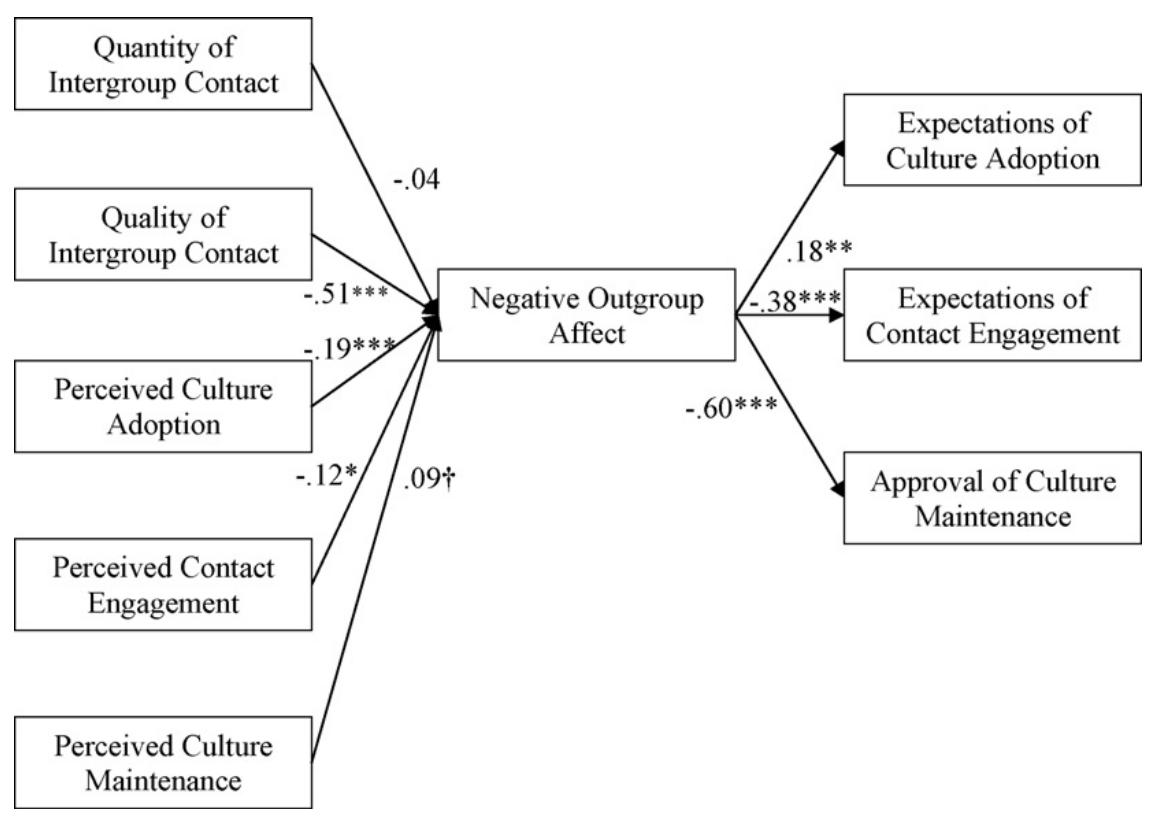

Fig. 2. Standardized estimates for the paths in the proposed model (unstandardized estimates for all variances, covariances and paths appear in Table 2 ). $\chi^{2}(15, N=247)=17.36, p=.30 ; C F I=100 ., G F I=.99, R M S E A=.025[.00 ; .068]$, SRMR $=.033 .{ }^{\dagger} p<.06,{ }^{*} p<.05,{ }^{* *} p<.01,{ }^{* * *} p<.001$.

Finally, Flemish host members' approval of Turkish' immigrants' culture maintenance was indirectly affected by perceived contact engagement $(\beta=.069, z=2.08, p<.05)$, perceived culture adoption $(\beta=.11, z=3.29, p<.001)$ and contact quality $(\beta=.31, z=7.31, p<.001)$. The indirect effect for perceived culture maintenance was marginally significant $(\beta=-.057$, $z=-1.89, p=.059)$.

\subsubsection{Model modification}

Because the effect of perceived culture maintenance on negative outgroup affect failed to reach significance, we tested whether our model could be improved by adding direct paths from perceived culture maintenance to expectations of contact engagement, expectations of culture adoption and approval of culture maintenance. This attempt to rebuild our model was inspired by Zagefka et al.s' (2007) observation that the effect of culture maintenance on preference for integration was not mediated by negative outgroup attitudes but appeared to operate directly. To explore this possibility we consulted the Lagrange Multiplier (LM) index for model building. LM estimates how much the overall model chi-square statistic would decrease if a particular fixed-to-zero path were freely estimated. Adding a direct path from perceived culture maintenance to approval of immigrants' culture maintenance $\left(\chi_{\text {diff }}^{2}(1, N=247)=0.01, p=.97\right)$ or to expectations of contact engagement $\left(\chi_{\text {diff }}^{2}(1, N=247)=2.49, p=.11\right)$ or to expectations of host culture adoption $\left(\chi_{\text {diff }}^{2}(1, N=247)=0.52, p=.42\right)$ did not improve our model. A multivariate LM allowing the three direct paths from perceived culture maintenance into the model did also not result in a significant decrease in chi-square $\left(\chi_{\text {diff }}^{2}(3, N=247)=2.59, p=.46\right)$. Thus, the proposed model cannot be improved by adding direct paths from perceived culture maintenance to the outcome variables.

\subsubsection{Alternative models with inverse causal directions}

Given that our data are cross-sectional, we next tested several additional models to rule out alternative theoretically sound orders in which the initial variables, the mediator, and the outcome variables could be placed.

In our proposed model majority members' perceptions of Turkish minority members' acculturation behavior are seen as predictor variables for Flemish majority members' own acculturation expectations because these perceptions would be more tight to reality than majority members' expectations (Zagefka et al., 2007). One could however also argue that Flemish majority members' perceptions of Turkish minority members' acculturation behavior are a component of their acculturation attitudes rather than a predictor of their acculturation expectations. A model that formalizes this alternative hypothesis considers perceived contact engagement, perceived culture adoption and perceived culture maintenance as outcome variables instead of as initial variables leaving everything else equal. This model did not fit the data as well as the proposed model $\left(\chi^{2}(12, N=247)=24.08, p<.05, C F I=.98 ; R M S E A=.064 ;\right.$ SRMR $\left.=.033\right)$.

Another alternative idea holds that Flemish majority members' expectations for Turkish minorities' acculturation guide their perceptions of reality and their experiences of intergroup contact which then in turn relate to more or less negative outgroup affect. A model that considers expectations of contact engagement, expectations of host culture adoption and approval of immigrants' culture maintenance as initial variables, the quantity and quality of intergroup contact and perceived contact engagement, perceived culture adoption and perceived culture maintenance as mediators and negative outgroup affect as outcome also did not fit the data well $\left(\chi^{2}(3, N=247)=64.25, p<.001 ; C F I=.88 ; R M S E A=.29 ; S R M R=.048\right)$. 
Table 2

Unstandardized estimates (and Standard Errors) for the proposed model A and model B.

\begin{tabular}{|c|c|}
\hline & Proposed model \\
\hline \multicolumn{2}{|l|}{ Variances } \\
\hline Quantity of intergroup contact & $1.020(.092)^{* * *}$ \\
\hline Quality of intergroup contact & $.80(.072)^{* * * *}$ \\
\hline Perceived contact engagement & $1.12(.10)^{* * *}$ \\
\hline Perceived culture adoption & $.33(.030)$ \\
\hline Perceived culture maintenance & $.36(.032)^{* * *}$ \\
\hline Negative outgroup affect & $.35(.031)^{* * *}$ \\
\hline Expectations of contact engagement & $.31(.028)^{* * * *}$ \\
\hline Expectations of culture adoption & $.37(.034)$ \\
\hline Approval of immigrants' culture maintenance & $.72(.064)^{* * *}$ \\
\hline \multicolumn{2}{|l|}{ Covariances } \\
\hline Quantity of intergroup contact, quality of intergroup contact & $.34(.062)^{* * *}$ \\
\hline Quantity of intergroup contact, perceived contact engagement & $.12(.069)$ \\
\hline Quantity of intergroup contact, perceived culture adoption & $.089(.038)^{*}$ \\
\hline Quantity of intergroup contact, perceived culture maintenance & $-.052(.039)$ \\
\hline Quality of intergroup contact, perceived contact engagement & $.41(.066)^{* * *}$ \\
\hline Quality of intergroup contact, perceived culture adoption & $.16(.034)^{* * *}$ \\
\hline Quality of intergroup contact, perceived culture maintenance & $-.046(.034)$ \\
\hline Perceived contact engagement, perceived culture maintenance & $-.14(.041)^{* * * *}$ \\
\hline Perceived culture adoption, perceived culture maintenance & $-.14(.024)^{* * * *}$ \\
\hline Perceived contact engagement, perceived culture adoption, & $.28(.043)^{* * * *}$ \\
\hline Expectations of contact engagement, approval of culture maintenance & $.025(.030)$ \\
\hline Expectations of culture adoption, approval of culture maintenance & $-.043(.033)$ \\
\hline Expectations of contact engagement, expectations of culture adoption & $.093(.022)^{* * *}$ \\
\hline \multicolumn{2}{|l|}{ Path coefficients } \\
\hline Quantity of intergroup contact $\rightarrow$ negative outgroup affect & $-.031(.040)$ \\
\hline Quality of Intergroup contact $\rightarrow$ negative outgroup affect & $-.48(.051)^{* * * *}$ \\
\hline Perceived contact engagement $\rightarrow$ negative outgroup affect & $-.091(.043)^{*}$ \\
\hline Perceived culture adoption $\rightarrow$ negative outgroup affect & $-.27(.079)^{* * *}$ \\
\hline Perceived culture maintenance $\rightarrow$ negative outgroup affect & $.13(.069)^{\dagger}$ \\
\hline Negative outgroup affect $\rightarrow$ expectations of contact engagement & $-.28(.042)^{* * *}$ \\
\hline Negative outgroup affect $\rightarrow$ expectations of culture adoption & $.13(.047)^{* *}$ \\
\hline Negative outgroup affect $\rightarrow$ approval of culture maintenance & $-.76(.042)^{* * *}$ \\
\hline
\end{tabular}

Note: Variances are variances from errors or disturbances of mentioned variable. Covariances are covariances between errors or disturbances of mentioned variables.

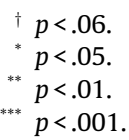

A variation on this idea holds that the amount of negative outgroup affect felt by majority members predicts their expectations of Turkish minority members' behavior which in turn guide their perceptions of Turkish minority members acculturation behavior and their experiences with interethnic contact. The third alternative model thus specified negative outgroup affect as initial variable, expectations of contact engagement, of host culture adoption and heritage culture maintenance as mediators and perceived host culture adoption, perceived heritage culture maintenance, perceived contact engagement and the quantity and quality of intergroup contact as outcome variables. This model did also not fit the data well $\left(\chi^{2}(5, N=247)=95.43, p<.001 ; C F I=.83 ; R M S E A=.27 ;\right.$ SRMR $\left.=.074\right)$.

\section{Discussion}

The present study shows that intergroup contact theory and acculturation theory can be genuinely combined to explain Flemish majority members' feelings towards Turkish immigrants as well as their expectations for the acculturation of Turkish minority group members. We have argued that majority members' expectations with regard to a minority group's acculturation behavior reflect the nature of their affective reactions towards this minority group. Majority members' affective reactions in turn are determined by their perceptions of this minority group's acculturation behavior and by their interpersonal contacts with this minority group. Our findings showed that positive contact experiences and perceiving that Turkish immigrants make efforts to engage in contact with the host group and/or to adopt the host culture are associated with less negative affective reactions towards Turkish migrants. Perceiving that Turkish immigrants maintain their heritage culture is associated with more negative affective reactions. Increased negative affective reactions in turn make it less likely that Flemish majority members approve heritage culture maintenance and consider intergroup contact very important while making it more likely that they demand culture adoption from Turkish minority members.

One possible way to interpret these patterns is in terms of an "exchange hypothesis" (see Curtis \& Miller, 1986). The exchange idea holds that if members of an immigrant group are perceived as making efforts to approach the host culture, 
majority members will be more positive towards this immigrant group and will be more inclined to tolerate this culture maintenance. However, Flemings seem to be convinced that Turkish minorities maintain their heritage culture to a larger extent than they are willing to adopt the host culture and to engage in contact with the host group. Since majority members tend to see more culture maintenance than approach tendencies among Turkish minority group members they may not be motivated to return the effort by tolerating culture maintenance. Thus, if the exchange hypothesis would be accurate, such a process could be at the basis of the persisting worrisome acculturation situation in Flanders.

This worrisome Flemish situation is further illustrated by the marked discrepancy between majority members' perceptions of Turks' behavior and their own preferences concerning Turkish immigrants' behavior. Host group members report that Turkish minority members maintain their heritage culture more strongly than they themselves like and they also report that Turkish minority members adopt the host culture to a smaller extent and that they engage in less contact with the host group than they would like (see Table 1 ).

Our data suggest that the present situation could be improved by increasing the possibilities for positive contact and by altering majority members' perceptions of a minority group's acculturation behavior. These two possible routes are by no means independent. One may argue that direct contact constitutes one way in which majority members form their perceptions about immigrants. On the other hand, majority members' perceptions may be affected by media messages (Schiappa, Gregg, \& Hewes, 2005) and these altered perceptions may influence one's inclination to look for contact. However, the present findings show that interethnic contact experiences and majority members' perceptions of a particular minority group's acculturation behavior have independent effects on their affective reactions and their acculturation expectations with respect to this minority group. This is important because the Flemish integration situation is such that the opportunities for intercultural contact are fairly limited as soon as one moves away from the larger cities. Future research should explore how majority members' perceptions of a particular immigrant group's acculturation behavior come about and how they can be modified, other than through direct contact. We need to investigate which behavioral patterns from the side of minority members are noticed by majority members so that they create and reinforce existing perceptions of strong heritage culture maintenance and limited host culture adoption. For instance, majority members' perceptions of Turks' culture maintenance may be grounded in perceived religious differences that manifest themselves in different domains (e.g., norms and values, customs, childrearing). This knowledge can then be used to set up programs to modify and differentiate existing perceptions. Within intergroup contact theory recent findings on extended contact, parasocial contact and even imagined contact suggest means for modifying perceptions. These types of contact may be especially effective if they would succeed in conveying the message that minority group members' adherence to some aspects of their heritage culture does not preclude neither regular contact with the host group members nor the adoption of elements of the host culture.

The present findings show that expectations of contact engagement and host culture adoption cannot be considered as equivalent in our sample. Thus, researchers should be careful when discussing and comparing results from studies that used different conceptualization of the acculturation dimensions. The data also clearly disconfirm the orthogonal structure of the fourfold acculturation model. This has repercussions for the applicability of fourfold acculturation theory across different acculturation situations. Moreover, the meanings of the four acculturation strategies are dubious in situations in which the independence assumption of acculturation theory does not hold. For instance, the concept of integration presumes that cultural practices are mere personal preferences that can be combined as one wishes to do so (Rudmin \& Ahmadzadeh, 2001). However, according to the Flemish majority members in this study, adoption of the Belgian host culture and maintenance of the Turkish minority culture are conflicting practices. In such a situation, integration becomes a questionable concept. Future researchers should first establish the relationship between both acculturation dimensions for the acculturating groups under study. The nature of this relationship may differ according to the acculturation domain (e.g., religion, language). If wanted, the kinds of strategies that prevail within a particular acculturating group may then be uncovered by clustering participants' responses to dimensional items (Rudmin, 2003).

In Section 1 we mentioned that we were hesitant to formulate predictions about the relationship between contact quantity and negative outgroup affect because of the rather negative intergroup climate present in Flanders with regard to Turkish immigrants. However, our data showed that the mere quantity of intergroup contact is associated with less negative affect (see Table 1) but this effect disappeared as soon as the quality of the contact was also taken into account. These findings are in line with Pettigrew and Tropp (2006) although they suggest that the positivity of interpersonal contact experiences is the more important determinant of majority members' affective response.

We acknowledge that the study has several limitations. One limitation is the cross-sectional design. Although we used SEM rather than conventional correlational techniques to study interrelations among variables, inferences about the causal direction of observed relationships still have to be formulated very cautiously. Experimental and longitudinal approaches are better placed to study the causal interplay between intergroup contact, acculturation perceptions and acculturation expectations. Second, by using single items to measure perceived acculturation behavior and acculturation expectations we did not cover different domains in which acculturation takes place and hence did not allow for differences between these domains. Future research could test whether the obtained relationships hold for different domains (e.g., private and public domains). Another limitation of the present study is that it was conducted in one specific intergroup context concerning one specific minority group (i.e. Turkish immigrants in Flanders). Future studies may also look at other contexts and other minority groups. Finally, the study was conducted among high school students and not among a representative sample of the population. We opted for this sample because high school students in Belgium form a more heterogeneous group in terms of SES and immigration attitudes and they tend to have more interethnic contact than college students and highly 
educated workers. But high school students' attitudes may differ from those of adults in that they may be less politicized. However, a recent study conducted in the Netherlands found no major differences between high school students' (between 14 and 15 years old) and adults' perceptions of minority members acculturation behavior and in their affective reactions to this behavior (Hofstra, Van Oudenhoven, \& Van der Zee, 2009a).

\section{Conclusion}

The present study aimed at explaining Flemish majority members' very demanding acculturation expectations with respect to Turkish immigrants. We showed that one reason why Flemish host group members are struggling with cultural diversity may be because they perceive that Turkish immigrants tend to maintain their heritage culture while showing only limited engagement in the host culture and this is experienced as threatening. To counter these beliefs it should be stressed that culture maintenance and efforts to participate in the host society can go hand in hand and that many minority members actually attempt to combine both strategies (Snauwaert et al., 2003). More carefully framed media portrayals as well as programs that foster interpersonal contact experiences can have beneficial effects.

\section{Acknowledgement}

The contribution of the first author was supported by a Ph.D. fellowship from the Research Foundation - Flanders (FWO).

\section{References}

Aberson, C. L., \& Haag, S. C. (2007). Contact, perspective taking, and anxiety as predictors of stereotype endorsement, explicit attitudes and implicit attitudes. Group Processes E' Intergroup Relations, 10, 179-201.

Allport, G. W. (1954). The nature of prejudice. Cambridge, MA: Addison-Wesley.

Amir, Y. (1969). Contact hypothesis in ethnic relations. Psychological Bulletin, 71, 319-342.

Arbuckle, J., \& Wothke, W. (1999). AMOS 4.0 user's guide. Chicago: Small Waters.

Batson, C. D., Polycarpou, M. P., Harmon-Jones, E., Imhoff, H. J., Mitchener, E. C., Bednar, L. L., \& Highberger, L. (1997). Empathy and attitudes: Can feeling for a member of a stigmatized group improve feelings toward the group? Journal of Personality and Social Psychology, 72, 105-118.

Berry, J. W. (1980). Acculturation as varieties of adaptation. In A. Padilla (Ed.), Acculturation: Theory, models and some new findings (pp. 9-25). Boulder, CO: Westview.

Berry, J. W. (2001). A psychology of immigration. Journal of Social Issues, 57(3), 615-631.

Berry, Kalin, \& Taylor. (1977). Multiculturalism and ethnic attitudes in Canada. Ottawa, Ontario, Canada: Supply and Services.

Berry, J. W., Kim, U., Power, S., Young, M., \& Bujaki, M. (1989). Acculturation attitudes in plural societies. Applied Psychology: An International Review, 38, 185-206.

Billiet, J., \& Swyngedouw, M. (2009). [Ethno-cultural minorities and the Flemish voters. An analysis on the basis of postelectoral surveys 1991-1995-19992003-2007] Etnische minderheden en de Vlaamse kiezers: Een analyse op basis van de postelectorale verkiezingsonderzoeken 1991-1995-1999-2003-2007 (D/2009/1191/1). Belgium: Katholieke Universiteit Leuven, Centrum voor Sociologisch Onderzoek.

Bokshandschoenen na 18 jaar terug [Boxing gloves back after 18 years]. (2009, January 19). De Standaard, pp. 6, 7.

Bourhis, R. Y., Moïse, L. C., Perreault, S., \& Senécal, S. (1997). Towards an interactive acculturation model: A social psychological approach. International Journal of Social Psychology, 32, 369-386.

Curtis, R. C., \& Miller, K. (1986). Believing another likes or dislikes you: Behaviors making the beliefs come true. Journal of Personality and Social Psychology, $51,284-290$.

ESS (European Social Survey). (2002). Downloadable from: www.europeansocialsurvey.org/.

EVS (European Value Survey). (2000). Downloadable from: www.europeanvaluesstudy.eu/.

González, R., Sirlopú, D., \& Kessler, T. (in press). Intergroup attitudes among Peruvians and Chileans as a function of identity, intergroup contact, acculturation preferences and intergroup emotions. Journal of Social Issues, 66(4).

Hofstra, J., Van Oudenhoven, J. P., \& Van der Zee, K. I. (2009a). Attachment styles and acculturation attitudes of adolescent and adult majority members, Manuscript submitted for publication.

Judd, C. M., Park, B., Ryan, C. S., Brauer, M., \& Kraus, S. (1995). Stereotypes and ethnocentrism: Diverging interethnic perceptions of African American and White American youth. Journal of Personality and Social Psychology, 69, 460-481.

Kline, R. B. (1998). Principles and practice of structural equation modeling. New York: Guilford Press.

Kosic, A., Mannetti, L., \& Sam, D. L. (2005). The role of majority attitudes towards out-group in the perception of the acculturation strategies of immigrants. International Journal of Intercultural Relations, 29, 273-288.

Mackie, D. M., Devos, T., \& Smith, E. R. (2000). Intergroup emotions: Explaining offensive action tendencies in an intergroup context. Journal of Personality and Social Psychology, 79, 602-616.

MacKinnon, D. P., Lockwood, C. M., Hoffman, J. M., West, S. G., \& Sheets, V. (2002). A comparison of methods to test mediation and other intervening variable effects. Psychological Methods, 7, 83-104.

Meeus, J., Duriez, B., Vanbeselaere, N., Phalet, K., \& Kuppens, P. (2009). Examining dispositional and situational effects on outgroup attitudes. European Journal of Personality, 23, 307-328.

Meeus, J., Braeken, J., Duriez, B., Vanbeselaere, N., Phalet, K. \& Mesquita, B. (2009). The effect of perceived discrepancies in acculturation attitudes: Testing the interactive acculturation model, Unpublished manuscript, Department of Psychology, K.U. Leuven, Leuven, Belgium.

Miller, D. A., Smith, E. R., \& Mackie, D. M. (2004). Effects of intergroup contact and political predispositions on prejudice: Role of intergroup emotions. Group Processes E Intergroup Relations, 7, 221-237.

Montreuil, A., \& Bourhis, R. Y. (2004). Acculturation orientations of competing host communities towards valued and devalued immigrants. International Journal of Intercultural Relations, 28, 507-532.

Pettigrew, T. F. (1998). Intergroup contact theory. Annual Review of Psychology, 49, 65-85.

Pettigrew, T. F., \& Tropp, L. R. (2006). A meta-analytic test of intergroup contact theory. Journal of Personality and Social Psychology, 90(5), $751-783$.

Phalet, K., Deboosere, P., \& Bastiaenssen, V. (2007). Old and new inequalities in educational attainment: Ethnic minorities in the Belgian Census 1991-2001. Ethnicities, 7, 390-415.

Phalet, K., Derycke, L., \& Swyngedouw, M. (1999). Culturele waarden en acculturatievormen bij Turken en Marokkanen in Brussel. In M. Swyngedouw, K. Phalet, \& K. Deschouwer (Eds.), Minderheden in Brussel. Sociopolitieke houdingen en gedragingen (pp. 41-74). Brussels, Belgium: VUB Press.

Phalet, K., \& Kosic, A. (2006). Acculturation in European societies. In D. Sam, \& J. W. Berry (Eds.), The Cambridge handbook of acculturation psychology (pp. 331-348). Cambridge, UK: Cambridge University Press. 
Piontkowski, U., Florack, A., Hoelker, P., \& Obdrzálek, P. (2000). Predicting acculturation attitudes of dominant and non-dominant groups. International Journal of Intercultural Relations, 24, 1-26.

Rohman, A., Florack, A., \& Piontkowski, U. (2006). The role of discordant acculturation attitudes in perceived threat: An analysis of host and immigrant attitudes in Germany. International Journal of Intercultural Relations, 30, 683-702.

Rudmin, F. W. (2003). Critical history of the acculturation psychology of assimilation, separation, integration, and marginalization. Review of General Psychology, 7, 3-37.

Rudmin, F. W., \& Ahmadzadeh, V. (2001). Psychometric critique of acculturation psychology: The case of Iranian migrants in Norway. Scandinavian Journal of Psychology, 42, 41-56.

Schiappa, E., Gregg, P. B., \& Hewes, D. E. (2005). The parasocial contact hypothesis. Communication Monographs, 72, 92-115.

Snauwaert, B. (2002). A social-psychological study on acculturation orientations of ethnic minority members and autochtons. Unpublished Doctoral Dissertation. Belgium: University of Leuven.

Snauwaert, B., Soenens, B., Vanbeselaere, N., \& Boen, F. (2003). When integration does not necessarily imply integration: Different conceptualizations of acculturation orientations lead to different classifications. Journal of Cross-Cultural Psychology, 34, $231-239$.

Stephan, W. G., Ybarra, O., Martinez, C., Schwarzwald, J., \& Tur-Kaspa, M. (1998). Prejudice toward immigrants to Spain and Israel: An integrated threat theory analysis. Journal of Cross-Cultural Psychology, 29, 559-576.

Stephan, W. G., Boniecki, K. A., Ybarra, O., Bettencourt, A., Ervin, K. S., Jackson, L. A., et al. (2002). The role of threats in the racial attitudes of Blacks and Whites. Personality and Social Psychology Bulletin, 28, 1242-1254.

Tropp, L. R., \& Pettigrew, T. F. (2005). Differential relationships between intergroup contact and affective and cognitive dimensions of prejudice. Personality and Social Psychology Bulletin, 31, 1145-1158.

Vanbeselaere, N., Meeus, J., \& Boen, F. (2007). 'Integratie’ van minderheden: Een pleidooi voor conceptuele zuiverheid. In B. Raymaekers, G. Van Riel, \& B. Pattyn (Eds.), Ruimte voor kennis: Lessen voor de XXIste Eeuw (pp. 195-224). Leuven: Universitaire Pers.

van de Vijver, F.J. R., Helms-Lorenz, M., \& Feltzer, M.J. A. (1999). Acculturation and cognitive performance of migrant children in the Netherlands. International Journal of Psychology, 34, 149-162.

Van Oudenhoven, J. P., \& Eisses, A. (1998). Integration and assimilation of Moroccan immigrants in Israel and the Netherlands. International Journal of Intercultural Relations, 22, 293-307.

Van Oudenhoven, J. P., Prins, K., \& Buunk, B. (1998). Attitudes of minority and majority members towards adaptation of immigrants. European Journal of Social Psychology, 28(6), 995-1013.

Van Zomeren, M., Fischer, A. H., \& Spears, R. (2007). Testing the limits of tolerance: How intergroup anxiety amplifies negative and offensive responses to out-group initiated contact. Personality and Social Psychology Bulletin, 33, 1688-1699.

Verkuyten, M., \& Thijs, J.(2002). Multiculturalism among minority and majority adolescents in the Netherlands. International Journal of Intercultural Relations, 26, 91-108.

Wright, S. C., Aron, A., McLaughlin-Volpe, T., \& Ropp, S. A. (1997). The extended contact effect. Journal of Personality and Social Psychology, 73, 73-90.

WVS (World Values Survey). (2000). Downloadable from: www.worldvaluessurvey.org/.

Zagefka, H., \& Brown, R. (2002). The relationship between acculturation strategies, relative fit and intergroup relations: Immigrant-majority relations in Germany. European Journal of Social Psychology, 32, 171-188.

Zagefka, H., Brown, R., Broquard, M., \& Martin, S. L. (2007). Predictors and consequences of negative attitudes towards immigrants in Belgium and Turkey: The role of acculturation preferences and economic competition. British Journal of Social Psychology, 46, $153-169$.

Zagefka, H., Brown, R., \& González, R. (2009). Antecedents and consequences of acculturation preferences of non-indigenous Chileans in relation to an indigenous minority: Longitudinal survey evidence. European Journal of Social Psychology, 39, 558-575. 